\title{
ПОЛІТОПІКАЛЬНІСТЬ ЯК ФАКТОР РЕКОНТЕКСТУАЛІЗАЦІЇ ПРЕДМЕТА ДУМКИ МОВЦЯ
}

У статті досліджено особливості реконтекстуалізації предмета думки мовця, зумовленої політопікальністю комунікації. Комунікативну інтеракцію за наявності перманентного предмета думки мовця визначено як монотопікальну. Керуючись комунікативною ініціативою, мовець детермінує топікальне поле для реалізації таких мовленнєвих ходів комунікативних партнерів.

Динамічна природа контекстуальних моделей передбачає постійні модифікації в процесі мовленнєвої взаємодії між комунікантами. Функційну переорієнтацію предмета думки мовця, яку супроводжують якісна та кількісна перебудови в структурі контекстуальних моделей, схарактеризовано як реконтекстуалізацію.

Установлено, що флуктуативність предмета думки мовця, тобто співіснування двох або більше предметів думки мовця, засвідчує політопікальність комунікації. Мовленнєві ходи комунікативних партнерів, будучи часто не пов'язаними між собою під час інтродукції нового предмета думки мовця, формують потенційне політопікальне поле комунікативної взаємодії.

Розкрито, що динамічна політопікальна інтеракція характеризується трансформацією ініціального предмета думки мовця в потенційні, зміною контекстуальних моделей комунікантів, появою нових перспектив на предмет обговорення, тобто реперспективацією, що часто має непередбачуваний і конфліктний характер.

Окреслено чинники, що в сукупності спричиняють політопікальність комунікації: епістемічний фактор (наявність інтелектуальної дистанції), афективний фактор (наявність психологічної дистанції), фактор перерозподілу комунікативних ролей (перехід комунікативної ініціативи від мовця до адресата) та фактор стороннього реципієнта, який змінює свій статус на активного реагента.

Звернуто увагу на вербальні й невербальні засоби експлікації політопікальності, що сигналізують про перспективну переорієнтацію предмета думки мовця в ході комунікативної взаємодії, «нашарування» перспектив комунікативних партнерів на предмет їх обговорення та, як наслідок, засвідчують мультиперспективність комунікативного процесу.

Ключові слова: політопікальність, реконтекстуалізація, предмет думки мовця, контекстуальна модель, мультиперспективність.

Вступ. Широкий спектр сучасних лінгвістичних розвідок сфокусований на дослідженні контексту та особливостей контекстуальних операцій (контекстуалізації, реконтекстуалізації, деконтекстуалізації) у процесі мовленнєвої взаємодії між комунікативними партнерами. Особливо актуальним $€$ їх фундаментальне переосмислення в когнітивно-комунікативній парадигмі.

У наукових працях $[2 ; 5 ; 7 ; 8 ; 11]$ контекст розглядають не як об'єктивно наявне утворення, а як особливий суб'єктивний конструкт - контекстуальну модель. Контекстуальна модель (KM) - це ментальна репрезентація релевантних вимірів комунікативної ситуації (мовець, адресат, стосунки між ними, їх знання, оцінки, емоції, місце та час комунікації) в епізодичній пам'яті комунікантів [7], яку генерує й трансформує кожен із них у ході мовленнєвої інтеракції.

На нашу думку, дослідження КМ доцільно проводити в органічному зв'язку 3 тематичним об'єктом комунікації - предметом думки мовця. Предмет думки мовия (ПДМ) визначаємо як когерентну агрегацію (накопичення) думок (позицій), що вводить мовець у дискурс і розвиває або сам мовець, або спільно з його співрозмовниками [5, с. 674].

Які б складні думки не виражали співрозмовники, вони завжди спиратимуться на ситуацію, у якій відбувається спілкування [4, с. 335], оскільки ПДМ є «концептуальною сутністю, що здатна реалізуватись в тексті та в контексті вербального і невербального типу» [3, с. 8].

КМ як когнітивний корелят комунікативної ситуації проєктується на процес мовленнєвої взаємодії комунікантів і здійснює контроль над контекстуалізацією (конкретизацією) ПДМ, таким чином забезпечуючи тематичну когерентність комунікації.

Розглянемо дотичну до контекстуалізації ПДМ контекстуальну операцію реконтекстуалізацію, яка націлена на функційну переорієнтацію ПДМ у процесі мовленнєвої взаємодії між комунікативними партнерами.

(C) Ковальчук Л., 2020 
Наукова розвідка ставить за мету спробу дослідити комунікативні особливості реконтекстуалізації ПДМ, зумовленої політопікальністю комунікації. Досягнення поставленої мети вимагає виконання таких завдань: розкрити динаміку політопікальної інтеракції; виявити чинники політопікальності, які спричиняють реконтекстулізацію ПДМ; проаналізувати вербальні та невербальні засоби політопікальності як фактора реконтекстуалізації ПДМ.

Методи та методика дослідження. Для студіювання політопікальності як фактора реконтекстуалізації ПДМ застосовано як загальнонаукові (аналіз, синтез, описовий, порівняльний), так і лінгвістичні методи дослідження (метод суцільної вибірки - для відбору та опрацювання ілюстративного матеріалу; метод контекстуально-інтерпретаційного аналізу - для розкриття динаміки політопікальної інтеракції, метод дискурсивного аналізу - для виявлення чинників політопікальності, які спричиняють реконтекстулізацію ПДМ; елементи конверсаційного аналізу - для аналізу вербальних і невербальних засобів експлікації політопікальності). На кожному етапі використано комплексну методику.

Результати та дискусії. Детальний аналіз ілюстративного матеріалу дав підставу виокремити визначальну функційну властивість КМ - динамічність, що зумовлена модифікаціями контекстуальних конфігурацій, як-от: перехід комунікативної ініціативи від мовця до адресата, поява інших учасників, зміна просторово-часових вимірів комунікативної ситуації тощо.

«Об'єктив» перебуває в постійному русі, він може бути наведений на той чи інший аспект комунікативної взаємодії, що виступає особливим різновидом фокусування уваги комунікантів. Певні елементи, які перебували у фокусі уваги, опиняються поза межами «об’єктива», постійно з'являються нові [11, с. 144].

Кваліфікуючи КМ як динамічне утворення, вважаємо доцільним виокремити ініціальну та потенційну КМ. Ініціальна КМ містить інформацію не лише про поточну комунікативну ситуацію, а й про дії й події, що їй передують. Унаслідок можливої зміни конфігурації складових частин ініціальної КМ (KMI) шляхом доповнення новою релевантною інформацією стосовно ПДМ генеруються похідні від неї - потенційні КМ (KM2, KM3 ... KMn).

Нова інформація може бути включена в КМ саме там, де вона буде необхідна для ідентифікації ПДМ, а не довільно. Лише в окремих випадках постає потреба повної трансформації вихідної моделі в такому процесі оновлення [6, с. 94].

Прогресію КМ у межах мовленнєвої взаємодії між комунікативними партнерами представимо таким чином: $K M 1 \rightarrow K M 2 \rightarrow K M 3 \rightarrow \ldots K M n$. Це переформатування КМ відносно ПДМ визначаємо як реконтекстуалізацію.

Реконтекстуалізація (термін Дж. Гамперца [10]) ПДМ - це лінгвокогнітивна операція, що полягає у використанні комунікантами вербальних та невербальних засобів із метою переорієнтації ПДМ у зв’язку зі зміною конфігурації складових КМ.

Результати дослідження засвідчують, що для значної частини комунікативних ситуацій характерна монотопікальність (наявність перманентного (фіксованого) ПДМ), за якою мовленнєва взаємодія між комунікативними партнерами відбувається тематично когерентно та гладко. Мовець, керуючись комунікативною ініціативою, своїм мовленнєвим ходом визначає топікальне поле для реалізації наступних мовленнєвих ходів (як власних, так і адресата), які взаємодоповнюються й розкривають різні аспекти ПДМ.

Однак доволі частотні також такі мовленнєві інтеракції, у ході яких ПДМ є флуктуативним (змінним). Співіснування двох або більше ПДМ у межах однієї комунікативної події визначаємо як політопікальність. Загальний ПДМ є достатньо «вільним», а локальні ПДМ виникають один за одним, генеруючи потенційне політопікальне поле, у якому мовленнєві ходи мовця та адресата можуть бути частково або абсолютно не пов'язані між собою.

Інколи така зміна теми відбувається досить різко, не будучи підготовленою безпосередньо попереднім мовленнєвим ходом дискурсу, некогерентно, на відміну від плавного, так би мовити, «еволюційного» розвитку глобальної теми в когерентній послідовності локальних тем [12, с. 146].

Розглянемо наступний приклад реконтекстуалізації ПДМ, у якому для зручності аналізу мовця й адресата як активних реагентів комунікативної інтеракції позначено, відповідно, $A P 1$ та $A P 2$. 
AP1 «What happened to you? You are hurt! There's blood on your face», Cathryn said solicitously.

Charles wiped under his nose with the back of his hand and stared at the flakes of dried blood.

AP1 «Are you going to tell me where you've been and what happened?» asked Cathryn finally.

AP2 «I'd rather hear about Michelle first», said Charles, putting the glass on the table.

AP1 «Please come down», said Cathryn gently.

AP2 «Then tell me what's happened to Michelle».

$\boldsymbol{A P 1}$ «It's just her fever», said Cathryn. «It's gone up and the doctors are concerned».

AP2 «Oh God», said Charles (R. Cook, 190).

У наведеному фрагменті вербальної інтеракції Катрін (мовець - AP1), помітивши сліди крові на обличчі Чарльза (адресата - AP2), прагне дізнатися, що з ним трапилося (What happened to you?). Проте, за ініціативою Чарльза, комунікативні партнери раптово переключаються на інший предмет обговорення - стан здоров'я доньки Мішель (I'd rather hear about Michelle first), який, на думку Чарльза, є вагомішим. Це сигналізує про реконтекстуалізацію ПДМ, спричинену політопікальністю.

Цей процес представимо за допомогою такої формули:

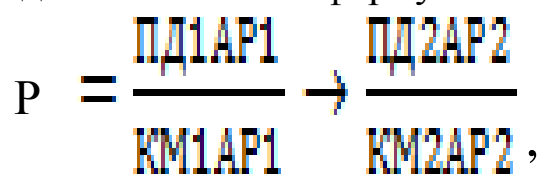

де $P$ - реконтекстуалізація, ПД1AP1 - ініціальний предмет думки $A P 1$ (мовця), ПД2AP2 потенційний предмет думки $A P 2$ (адресата), $K M 1 A P 1$ - контекстуальна модель $A P 1, K M 2 A P 2$ контекстуальна модель $A P 2$.

Реконтекстуалізація ПДМ, передусім, нерозривно пов'язана з топікальною перспективою, тобто особливим способом бачення, розуміння та оцінювання комунікантами предмета їхнього обговорення. Топікальна перспектива, як і контекстуальна модель, є динамічним явищем, тобто вона може варіюватись у процесі комунікації. Асиметрія топікальних перспектив співрозмовників на ПДМ спричиняє реперспективацію, тобто зміну перспективи на предмет обговорення.

Напружені дискусії, які розвиваються динамічно й часто непередбачувано, нагадують розмови конференц-зв'язку, у якому топіки з'являються, зникають або розгалуджуються на цілком інші топіки, залишаються або трансформуються зі зміною контекстів $\mathrm{i}$, як наслідок, 3'являються нові перспективи на частково ті самі, а частково нові теми розмови. Ці процеси реперспективації таким способом реконтекстуалізують трактування певних подій у дискурсі, що мають довготривалий характер [9, с. 52].

Ретельний аналіз лінгвальних ресурсів засвідчив, що до чинників, які у своїй сукупності спричиняють політопікальність комунікації, належать:

- епістемічний фактор (наявність інтелектуальної дистанції);

- афективний фактор (наявність психологічної дистанції);

- фактор перерозподілу комунікативних ролей (перехід комунікативної ініціативи від мовця до адресата);

- фактор стороннього реципієнта, який змінює свій статус на активного реагента.

Реалізація епістемічного фактора політопікальності виникає внаслідок наявності інтелектуальної дистанції між комунікативними партнерами, тобто через відсутність або різнооб'ємність спільного фонду знань, неоднаковий ступінь інформованості стосовно ПДМ, різний рівень освіченості та інтелектуальної обізнаності, що перешкоджає їх взаєморозумінню.

Акт спілкування $є$ незбалансованим, якщо в ролі співбесідника є людина, фонові знання якої значно відрізняються від фонових знань ініціатора комунікативного акту (модель «ми говоримо різними мовами») [1, с. 219].

AP1 «What are we to do with him?» he [Mr. Emerson] asked. «He comes out for his holiday to Italy, and behaves - like that; like the little child who ought to have been playing, and who hurt himself upon the tombstone. Eh? What did you say?» 
Lucy had made no suggestion.

AP1 «I only know what it is that's wrong with him; not why it is».

AP2 «And what is it?" asked Lucy fearfully.

AP1 «The old trouble; things won't fit».

AP2 "What things?»

$A P 1$ «The things of the universe. It is quite true. They don't».

AP2 «Oh, Mr. Emerson, whatever do you mean?»

To this extraordinary speech Lucy found no answer. After a short pause she started quoting poetry.

AP2 «From far, from eve and morning, And yon twelve-winded sky, The stuff of life to knit me Blew hither: here am I» (E. Foster, 25).

Як бачимо, причиною політопікальності наведеної вище комунікативної події $\epsilon$ інтелектуальна дистанція між мовцем та адресатом. Містер Емерсон говорить про свого учня Джорджа (What are we to do with him?), проте Люсі не ідентифікує ПДМ, оскільки в іi індивідуальному когнітивному просторі об'єкт референції відсутній. Саме значна інтелектуальна дистанція зі сторони адресата орієнтована на комунікативну інтенцію запиту (And what is it? What things? Whatever do you mean?), яка доповнюється його негативною емоційною реакцією (asked fearfully). У відповідь на комунікативний стимул співрозмовника Люсі інтродукує та реконтекстуалізує новий ПДМ, цитуючи уривок поезії (I only know what it is that's wrong with him; not why it is. The old trouble; things won't fit; The things of the universe. It is quite true. They don't; From far, from eve and morning, And yon twelve-winded sky, The stuff of life to knit me Blew hither: here am I).

Афективний фактор політопікальності експлікується через значну психологічну дистанцію - низький ступінь емоційно-ціннісної близькості між комунікативними партнерами, яка відображає відносини дисгармонії, що супроводжуються негативністю (незадоволенням, розчаруванням, обуренням, гнівом, роздратуванням, розгубленістю, страхом) та відсутністю прагнення до взаємодії.

Вербальними засобами вираження негативних емоцій стосовно ПДМ слугують синтаксичні структури, представлені окличними реченнями, та лексичні засоби різної частиномовної приналежності, які формують фонд емотивних засобів мови: прикметники (angry, disappointed, dissatisfied, displeased, frustrated, transfixed, irritated, sullen, vicious, uncomfortable, etc.); іменники (dissatisfaction, disappointment, frustration, disillusionment, disgust, disapproval, indignation, anger, rage, irritation, doubt, fear, anxiety, perplexity, resentment, revolt, etc.); дієслова (doubt, groan, grumble, disturb, enrage, disappoint, irritate, frighten, etc.); прислівники (terribly, awfully, wistfully, gruffly, anxiously, abruptly, suspiciously, etc.); вигуки (Gosh! Oh my God! Damn it all! Fuck!).

Засоби кінесики (жести й мімічні рухи), проксеміки (відстань між комунікантами та їхні пози під час спілкування), такесики (потискання рук, дотики), просодики (темп і манера мовлення) є невербальними маркерами експлікації емоцій стосовно ПДМ.

Mr. Perkins went on.

API «I'm disappointed with you. And I can't understand. I know you can do things if you want to, but you don't seem to want to any more. I was going to make you a monitor next term, but I think I'd better wait a bit».

Philip flushed. He did not like the thought of being passed over. He tightened his lips.

AP1 «And there's something else. You must begin thinking of your scholarship now. You won't get anything unless you start working very seriously».

Philip was irritated by the lecture. He was angry with the headmaster, and angry with himself.

AP2 «I don't think I'm going up to Oxford. I've changed my mind. Let me raise another subject...», he said.

Mr. Perkins drew his fingers thoughtfully through his beard (W. S. Maugham, 125).

У наведеному фрагменті розмови проявом психологічної дистанції між директором школи містером Перкінсоном та учнем Філіппом $\epsilon$ їхні дисонантні оцінки та негативні емоції стосовно ПДМ - незадовільні успіхи в навчанні, що, урешті, породжує політопікальність мовленнєвої взаємодії (Let me raise another subject). Розчарування мовця експліковано як 
вербально (disappointed, can't understand), так і невербально (drew his fingers thoughtfully through his beard). Роздратування адресата щодо ПДМ представлено вербальними (irritated, angry) та невербальними сигналами (flushed, tightened his lips). Когнітивні розбіжності й емоційні тертя комунікантів стосовно ПДМ засвідчуть їх конфліктне спілкування та дивергенцію КМ.

Фактор перерозподілу комунікативних ролей реалізується як перехід комунікативноі ініціативи від мовия до адресата у формі добровільної «передачі» або самовільного «захоплення». Адресат змінює свою субординуючу позицію інтерпретатора на домінуючу позицію ініціатора ПДМ. Така «ротація» неодмінно спричиняє якісну перебудову КМ, тобто реконтекстуалізацію.

Новий мовець створює силове поле, яке взаємодіє з полем першого мовця. Воно має свій центр і свою периферію, своє вживання знаків «тут» і «зараз». Обстановка спілкування може бути збережена. А енергетичний «заряд» висловленню надає його автор. Виникає складне багатополюсне енергетичне поле, у якому відбувається зміна центрів комунікативного простору $[13$, c. 216$]$.

Для перебирання комунікативної ініціативи адресат досить часто застосовує тактику перебивання або привертання уваги, щоб збільшити інтерес мовця до нового предмета обговорення та заохотити до подальших сумісних комунікативних дій. Вербальними засобами реалізації цих тактик слугують спеціальні розмовні кліше типу I say..., Look here..., What about...? How about...? тощо.

AP1 «I'm not in the least sorry. Of course, it's just waste of money keeping me on at school».

$A P 2$ «Is it true that you're very anxious to leave?»

$A P 1 \ll Y e s$, sir».

AP2 «Are you unhappy here?»

Philip blushed. He hated instinctively any attempt to get into the depths of his feelings.

$A P 1 \ll O h$, I don't know, sir».

Mr. Perkins seemed to speak almost to himself. AP2 «Of course, schools are made for the average...». Then suddenly he addressed himself to Philip: "Look here, I've got a suggestion to make to you. If you want to go to Germany you'd better go after Easter than after Christmas...» (W. S. Maugham, 138).

В аналізованому прикладі «затінення» ПДМ (it's just waste of money keeping me on at school) зі сторони мовця Філіппа експлікується його негативною вербальною (waste of топеy) та невербальною (blushed) евалюацією. Водночас адресат містер Перкінс, застосовуючи тактику привертання уваги, удається до реконтекстуалізації, інтродукуючи новий ПДМ (I've got a suggestion to make to you), про що сигналізують вербальний (Look here) і невербальний (suddenly addressed) засоби.

Обов'язковими учасниками канонічної мовленнєвої взаємодії в найпростішому іiї варіанті $\epsilon$ мовець та адресат. Проте, за результатами нашого дослідження, доволі поширеними $\epsilon$ комунікативні ситуації за наявності третього антропокомнонента - стороннього реципієнта, який перебуває в зоні аудіо-сприйняття вербального контакту між інтерактантами й здатен виступити в ролі інтерпретатора змісту повідомлення [14, с. 13], керуючись власною КМ.

Як зазначає Г. Браун, коли з'являється третя особа, додається ще один новий контекст [2, с. 28-29]. Така «ротація» неодмінно спричиняє не лише якісну, а й кількісну перебудову КМ, в результаті якої формується КМ із розширеною антропоструктурою.

Фактор стороннього реципіснта має особливу релевантність, коли сторонній реципієнт змінює свій комунікативний статус із пасивного стостерігача на активного реагента й бажає інтродукувати власний ПДМ.

На цей раз процес реконтекстуалізації ПДМ представимо таким чином:

$$
\mathrm{P}=\frac{\Pi \mathrm{M} 1 \mathrm{AP} 1}{\mathrm{KM} 1 \mathrm{AP} 1} \rightarrow \frac{\Pi \mathrm{M} 1 \mathrm{AP} 2}{\mathrm{KM} 2 \mathrm{AP} 2} \rightarrow \frac{\Pi \mathrm{M} 2 \mathrm{CP}}{\mathrm{KM} 3 \mathrm{CP}}
$$


де $P$ - реконтекстуалізація, ПД1AP1 - ініціальний предмет думки $A P 1$ (мовця), ПД1AP2 предмет думки $A P 2$ (адресата), ПД2CP - потенційний предмет думки $C P$ (стороннього реципієнта), $K M 1 A P 1$ - контекстуальна модель $A P 1$, KM2AP2 - контекстуальна модель $A P 2$, $K M 3 C P$ - контекстуальна модель стороннього реципієнта.

Зазвичай сторонній реципієнт задля реконтекстуалізації ПДМ удається до використання тактики «взяття слова», про що свідчать «фактичні» мовленнєві ходи на зразок «Ехсиsе те, may I ask you?», «Sorry for interrupting you, but...» тощо.

Покажемо це на прикладі, де стороннього реципієнта позначимо CP:

The studio was large and bare, with gray walls, on which were pinned the studies that had received prizes. A model was sitting in a chair with a loose wrap thrown over her.

AP1 «Oh, there's nothing like that here», she [Mrs. Otter] said. "You see, about half our students are ladies, and they set a tone to the place». Then she turned to the model. «La Pose».

AP2 «It's a stupid pose», said Miss Price. "I can't imagine why they chose it».

When Philip entered, the people in the studio had looked at him curiously, and the model gave him an indifferent glance, but now they ceased to pay attention to him. Philip, with his beautiful sheet of paper in front of him, stared awkwardly at the model. He did not know how to begin. He glanced at Miss Price's work.

CP «Sorry for interrupting you, but I should have thought I could do as well as that», he said (W. S. Maugham, 286-287).

Зміну статусу стороннього реципієнта (entered, with his beautiful sheet of paper in front of him, stared awkwardly at the model) на активного реагента, який реконтекстуалізує новий ПДМ, маркують вербальний (I should have thought I could do as well as that) та невербальний (glanced at Miss Price's work) сигнали. Мовленнєвий хід «Sorry for interrupting you, but...» засвідчує реалізацію тактики «взяття слова».

Висновки. Отже, як засвідчив проведений аналіз, для політопікальності як фактора реконтекстуалізації предмета думки мовця суттєвими є чинники наявності інтелектуальної та психологічної дистанції, переходу комунікативної ініціативи від мовця до адресата й присутності стороннього реципієнта як активного реагента. Як наслідок, процес реконтекстуалізації предмета думки мовця, зумовлений політопікальністю комунікації, характеризується топікальною мультиперспективністю - «нашаруванням» перспектив комунікативних партнерів на предмет їх обговорення.

На нашу думку, релевантним для подальших лінгвістичних розвідок є дослідження гендерних особливостей політопікальності комунікації як фактора реконтекстуалізації предмета думки мовця.

References
1. Batsevych, Fedir. 2004. Osnovy komunikatyvnoyi linhvistyky. Kyiv: Akademiya.

2. Brown, Gillian. 1995. Speakers, Listeners and Communication: Explorations in Discourse Analysis. Cambridge: Cambridge University Press.

3. Bulatetska, Liudmyla. 1997. "Interpretatsiya predmeta dumky movtsya ta umovy yiyi komunikatyvnoi syntahmatyky". Naukovyi visnyk VNU imeni Lesi Ukrainky 5: 8-10.

4. Bulygina, Tetyana. 1997. Yazykovaya kontseptualizatsyya mira. Moskva: Shkola "Yazyki russkoy kultury".

5. Chafe, Wallace. 2003. The Analysis of Discourse Flow: The Handbook of Discourse Analysis. Blackwell Publishing.

6. Deyk, Toyn A. van. 1989. Yazyk. Poznaniye. Kommunikatsyya. Moskva: Progress.

7. Dijk, Teun A. van. 2008. Discourse and Context: A Sociocognitive Approach. New York: Cambridge University Press.

8. Duranti, Alessandro and Goodwin, Charles. 1995. Rethinking Context. Cambridge: Cambridge University Press.

9. Graumann, Carl F., Kallmeyer, Werner. 2002. Perspective and Perspectivation in Discourse. Amsterdam / Philadelphia: John Benjamins Publishing Company.

10. Gumperz, John J. 1982. Discourse Strategies: Studies in Interactional Sociolinguistics. Cambridge: Cambridge University Press.

11. Langacker, Ronald W. 2001. "Discourse in Cognitive Grammar". Cognitive Linguistics 2: 43-188.

12. Makarov, Mikhail. 2003. Osnovy teorii diskursa. Moskva: Gnosis.

13. Susov, Ivan. 2009. Lingvisticheskaya pragmatika. Vinnitsa: Novaya kniga. 
14. Vorontsona, Natalia. 2009. Komunikatyvna interaktsiia zi storonnim retsypiientom: lingvopragmatychnyi $i$ kognityvnyi aspekty. Kremenets.

15. Cook, Robin. 1982. Fever. New York: New American Library.

16. Forster, Edward. 1998. A Room with a View. London: Penguin Books.

17. Maugham, W. Somerset. 1991. Of Human Bondage. New York: Bantam Classics.

Ковальчук Людмила. Политопикальность как фактор реконтекстуализации предмета мысли говорящего. В статье исследуются особенности реконтекстуализации предмета мысли говорящего, обусловленной политопикальностью коммуникации. Коммуникативную интеракцию при наличии перманентного предмета мысли говорящего определяем как монотопикальную. Руководствуясь коммуникативной инициативой, говорящий детерминирует топикальное поле для реализации последующих речевых ходов коммуникативных партнеров.

Динамическая природа контекстуальных моделей предполагает постоянные модификации в процессе речевого взаимодействия между коммуникантами. Функциональная переориентация предмета мысли говорящего, которая сопроводжается качественной и количественной перестройкой в структуре контекстуальных моделей, характеризируется как реконтекстуализация.

Установлено, что флуктуативность предемета мысли говорящего, то есть сосуществование двух или более предметов мысли говорящего, свидетельствует о политопикальности коммуникации. Речевые ходы коммуникативных партнеров, будучи часто не связанными между собой при интродукции нового предмета мысли говорящего, формируют потенциальное политопикальное поле коммуникативного взаимодействия.

Раскрывается, что динамическая политопикальная интеракция характеризуется трансформацией инициального предмета мысли говорящего в потенциальные, изменением контекстуальных моделей коммуникантов, появлением новых перспектив на предмет обсуждения, то есть реперспективацией, которая часто имеет непредсказуемый и конфликтный характер.

Определяются факторы, которые в своей совокупности порождают политопикальность коммуникации: эпистемический фактор (наличие интеллектуальной дистанции), аффективный фактор (наличие психологической дистанции), фактор перераспределения коммуникативных ролей (переход коммуникативной инициативы от говорящего к адресату) и фактор постороннего реципиента, меняющего свой статус на активного реагента.

Обращается внимание на вербальные и невербальные средства экспликации политопикальности, сигнализирующие о перспективной переориентации предмета мысли говорящего в ходе коммуникативного взаимодействия, «наслоении» перспектив коммуникативных партнеров на предмет их обсуждения и, как следствие, свидетельствующие о мультиперспективности коммуникативного процесса.

Ключевые слова: политопикальность, реконтекстуализация, предмет мысли говорящего, контекстуальная модель, мультиперспективность.

Kovalchuk Liudmyla. Polytopicality as a Factor of Topic Recontextualization. The article is devoted to the study of the peculiarities of the object of the speaker's thought recontextualization caused by the polytopicality of communication. The communicative interaction in the presence of the permanent object of the speaker's thought is defined as monotopical. Guided by the communicative initiative, the speaker determines the topical field for the implementation of the subsequent speech actions of communicative partners.

The dynamic nature of context models presupposes constant modifications in the process of speech interaction between communicators. Functional reorientation of the object of the speaker's thought accompanied by the qualitative and quantitative rearrangement in the structure of context models is described as recontextualization.

Reference has been made to the fluctuation of the object of the speaker's thought, that is the coexistence of two or more objects of the speaker's thought, that determines the polytopicality of communication. Communicative partners' speech actions, often unrelated when introducing the new object of the speaker's thought, form the potential polytopic field of the communicative interaction.

It has been revealed that dynamic polytopic interaction is characterized by the transformation of the initial object of the speaker's thought into potential ones, the change of context models of communicators, the emergence of new perspectives on the topic under discussion, that is reperspectivation, which is often of unpredictable and conflicting character.

The factors that together cause the polytopicality of communication have been singled out, such as the epistemic factor (the presence of intellectual distance), the affective factor (the presence of psychological distance), the factor of redistribution of communicative roles (the transition of the communicative initiative from the speaker to the addressee) and the factor of the side-recipient who changes his status to the active reagent.

Attention has been focused on verbal and non-verbal means of explication of polytopicality which signal the perspective reorientation of the object of the speaker's thought in course of communicative interaction, «layering» of communicative partners' perspectives on the topic under discussion and, consequently, testify to the multiperspectivity of the communicative process.

Key words: polytopicality, recontextualization, object of the speaker's thought, context model, multiperspectivity. 